\title{
Is Cropsyst adequate for management-oriented simulation of growth and yield of processing tomato?
}

\author{
Onofri Andrea*, Beccafichi Catia, Benincasa Paolo, Guiducci Marcello \\ and Tei Francesco
}

Department of Agricultural and Environmental Sciences, University of Perugia, Borgo XX giugno, 74, I-06121, Perugia (Italy).*E-mail: onofri@unipg.it

\begin{abstract}
The model CropSyst has proven useful for management-oriented simulations of growth and yield of cereals and other field crops, but no scientific information is available with reference to processing tomato. The aim of this paper was to parameterise and validate the crop module of CropSyst for the simulation of potential fruit production in processing transplanted tomato (Lycopersicon esculentum Mill.). Parameterisation and calibration were performed by using field data from an experiment carried out in 1997 in Central Italy. The same set of parameters was validated against five independent experiments, carried out on the same location in 1998, 1999, 2000, 2001 and 2002. The simulation of aerial biomass was always very good, with RRMSE values ranging from 7.5 to $13.4 \%$ and modelling efficiencies (EI) always above 0.976 . The simulation of LAI was very good during the first part of growing season (up to 40-50 days after transplanting), while the decreasing trend in the final part of growing cycle was not always reliably simulated. Indeed, RRMSE for LAI ranged from 13.5 to $26.8 \%$ and EI ranged from 0.849 to 0.966 . The differences between simulated and observed final fruit yield were below 10\%, except in one year (18\% in 2001), confirming the practical value of this model, for management and legislative purposes. For research purposes, it is confirmed that the simulation of dry matter partitioning is a crucial issue in vegetable crops such as tomato, wherein the growth of sources and sinks coexists for a main part of crop cycle.
\end{abstract}

Key words: Processing tomato, CropSyst, simulation, modelling, dry matter partitioning

\section{Introduction}

Tomato (Lycopersicon esculentum Mill.) is one of the most widespread summer crops in Mediterranean environments and it would be helpful to make predictions of yield, as affected by farming practices and environmental conditions. Among available models, CropSyst (Stöckle et al., 2003) may be particularly useful for practical applications oriented to field management and decision making, thanks to the very user-friendly interface, to the possibility of including several management events either on specific dates or synchronised with crop phenology, and to the possibility of simulating crop rotations.

With respect to other models, CropSyst introduces several conceptual simplifications and thus works with a smaller set of input parameters. For example, the core of the simulation engine for crop growth is based on two simple functions for radiationand transpiration-dependent growth (Stöckle and Nelson, 2003), which rely on two input parameters, i.e. the light-to-biomass conversion coefficient ( $L t B C$, as $\left.\mathrm{kg} \mathrm{MJ}^{-1}\right)$, and the water-tobiomass conversion ratio (BTR, as $\left.\mathrm{kg} \mathrm{m}^{-3} \mathrm{kPa}\right)$.

The approach to dry matter partitioning is also very simple and based on one empirical equation, with two main input parameters, the 'leaf area/plant biomass' ratio at the early growth stages ( $L A R$, as $\mathrm{m}^{2}$ leaves $\mathrm{kg}^{-1}$ plant) and the stem-leaf partition coefficient (SLP, as $\mathrm{m}^{2} \mathrm{~kg}^{-1}$ ), that accounts for the sharp decline of LAR as biomass accumulates over time (Stöckle and Nelson, 2003). On the other hand, dry matter partitioning to commercial yield is very simply simulated by multiplying final accumulated biomass by the harvest index (HI), eventually corrected by water stress during flowering and fruit ripening.
It has been shown that $L t B C, B T R, L A R$ and $S L P$, together with other phenological parameters, are those that more strongly affect simulation results and thus must be chosen with care (Confalonieri and Bechini, 2004; Donatelli et al., 1997; Pala et al., 1996).

The above-mentioned simplicity may be regarded as an advantage, because CropSyst is easily parameterised and calibrated. This may contribute to a high level of diffusion, outside research institutions and with very practical aims (legislative support, technical advice and so on). However, the use of CropSyst without an appropriate validation may easily lead to unreliable conclusions.

This is particularly true for tomato and other vegetable crops that show several ecophysiological differences with respect to cereals and other field crops, wherein CropSyst has been more extensively validated. In particular, the conceptual shortcuts introduced by CropSyst with reference to dry matter partitioning may hold for cereals, but may represent a problem in tomato, wherein the development of sources and sinks overlaps for a main part of crop cycle. It should not be forgotten that models developed for specific use in tomato adopt a more complex approach to biomass partitioning with respect to CropSyst (Van Keulen and Dayan, 1993; Heuvelink, 1996; Scholberg et al., 1997; Heuvelink, 1999; Ramirez et al., 2004; Boote and Scholberg, 2006). Scientific information on the reliability of CropSyst simulations with reference to growth and yield of tomato is not available.

Therefore, the aim of this study was to parameterise and validate the crop module of CropSyst, by using a series of field experiments carried out in Central Italy, on conventionally grown processing tomato. 


\section{Materials and methods}

Field experiments: Six field experiments were carried out in processing tomato (cv. PS1296) from 1996 to 1997 and from 1999 to 2002, at Papiano (Perugia, Central Italy, $43^{\circ} \mathrm{N}, 165$ m a.s.l.) on a silty-loam soil with $1.3 \%$ organic matter. These experiments compared development and growth of processing tomato at different $\mathrm{N}$-fertilisation and density levels, on plots of $100 \mathrm{~m}^{2}$ size. Results have been already published elsewhere (Tei et al., 1999, 2001, 2002; Benincasa et al., 2006). From these experiments, we selected only those experimental treatments wherein the crop was grown following ordinary practices with reference to seedbed preparation, transplanting (from 25 May to 3 June), plant density (always 3.2 plants $\mathrm{m}^{-2}$ with rows $0.9-1.2 \mathrm{~m}$ apart), $\mathrm{N}$-fertilisation (always $200 \mathrm{~kg} \mathrm{~N} \mathrm{ha}^{-1}$ ) and pest control. No limitations of growth were introduced by nutrient shortage, weeds or pests. All the details can be found in the cited papers.

In all the experiments 4-6 plants per plot were sampled throughout the growing season at approximately weekly intervals. At each sampling date, above ground dry weight and leaf area index (LAI) were determined. The main phenological indexes were also recorded as well as final commercial fruit yield at harvest time.

Daily meteorological data (maximum and minimum temperature, rainfall, global solar radiation and wind speed) were also collected from a station inside the experimental site.

Parameterisation, calibration and validation of CropSyst: Simulations were run by using CropSyst version 3.04.08 (29 March 2005). Potential evapotranspiration was estimated by using the Priestley-Taylor equation, while soil water redistribution was simulated by the cascade model.

CropSyst was parameterised by using default values, literature data and the experimental dataset obtained in 1997. A LtBC value of $2.4 \mathrm{~g} \mathrm{MJ}^{-1}$ was chosen from Cavero et al. (1998), that is perfectly in line with values found by Scholberg et al. (2000a, b) and Tei et al. (2002). Optimal mean temperature for plant growth was set at $20^{\circ} \mathrm{C}$ (Boote and Scholberg, 2006), while a value of 0.55 was chosen for the average extinction coefficient (k), following Ramirez et al. (2004) and Tei and Guiducci (unpublished data; see also Acock et al., 1978; Jones et al., 1991; Cavero et al., 1998).

On the other hand, LAR and SLP were estimated by fitting into the dataset of 1997 the following equation (Stockle et al., 2003):

$L A I=\frac{L A R \cdot D W}{1+S L P \cdot D W}$

where DW is the accumulated above-ground biomass $\left(\mathrm{kg} \mathrm{m}^{-2}\right)$, as recorded with increasing LAI values.

Initial and maximum LAI were taken from the 1997 experiment, as well as final LAI values with respect to maximum LAI. The harvest index (HI) was obtained from the same experiment, as the observed ratio between dry commercial fruit yield and total dry biomass at final harvest $(\mathrm{HI}=0.67)$. Such values are consistent with findings of Scholberg et al. (2000a) and Battilani (2006).

Also the phenological parameters required by CropSyst, i.e. Growing Degree Days [GDD $=\mathrm{T}_{\text {mean }}-\mathrm{T}_{\text {base }}$; where $\mathrm{T}_{\text {mean }}=$ $\left(\mathrm{T}_{\max }+\mathrm{T}_{\text {min }}\right) / 2$ ] for flowering, for reaching maximum LAI and for physiological maturity, were calculated from data observed in 1997 (Stöckle and Nelson, 2003). A $\mathrm{T}_{\text {base }}$ of $10^{\circ} \mathrm{C}$ (Scholberg et al., 2000a) and a $T_{\text {cutoff }}$ of $35^{\circ} \mathrm{C}$ (Boote and Scholberg, 2006) were assumed.

All the other parameters were initially set to default values and simulations were performed by using the dataset of 1997 to calibrate the BTR and maximum water daily uptake (mm).

After calibration, the model was validated by applying the calibrated set of parameters to all the other experiments (1996, 1999, 2000, 2001, 2002). The same set of parameters was always used, except for the initial LAI, that was regarded as an input datum for the model and was always set to the observed value. Such a decision was taken considering that in transplanted tomato the size of plants at transplanting may be very different from year to year; thus the same initial LAI does not hold in practice and may lead to considerable differences in modelling results (Tei et al., 1996a, b)

The agreement between observed and predicted values was expressed by using the Relative Root Mean Squared Error (RRMSE: minimum and optimum value $=0$ ) and the modelling efficiency (EF: optimal value $=1$ ), as indicated by Martorana and Bellocchi (1999).

\section{Results and discussion}

The whole set of crop parameters as used in simulations is reported in Table 1 . The calibrated value for the water to biomass conversion coefficient (BTR) is much higher than those reported in the CropSyst manual (maxima of 6.0 and $8.5 \mathrm{~kg} \mathrm{~m}^{-3} \mathrm{kPa}$ respectively for $C_{3}$ and $C_{4}$ species; Stöckle and Nelson, 2003). Unfortunately, it was not possible to lower the BTR value below $10.72 \mathrm{~kg} \mathrm{~m}^{-3} \mathrm{kPa}$ without severely degrading the quality of simulations.

The relationship between LAI and accumulated dry biomass (Eq. 1) in 1997 (Fig. 1) was used to obtain a reliable estimate of LAR and SLP as shown by low standard errors (12.194 \pm 0.873 and $1.368 \pm 0.249$ ).



Fig. 1. Relationship between above ground biomass and LAI. Symbols show observed data (1997), solid line shows fitted curve. 

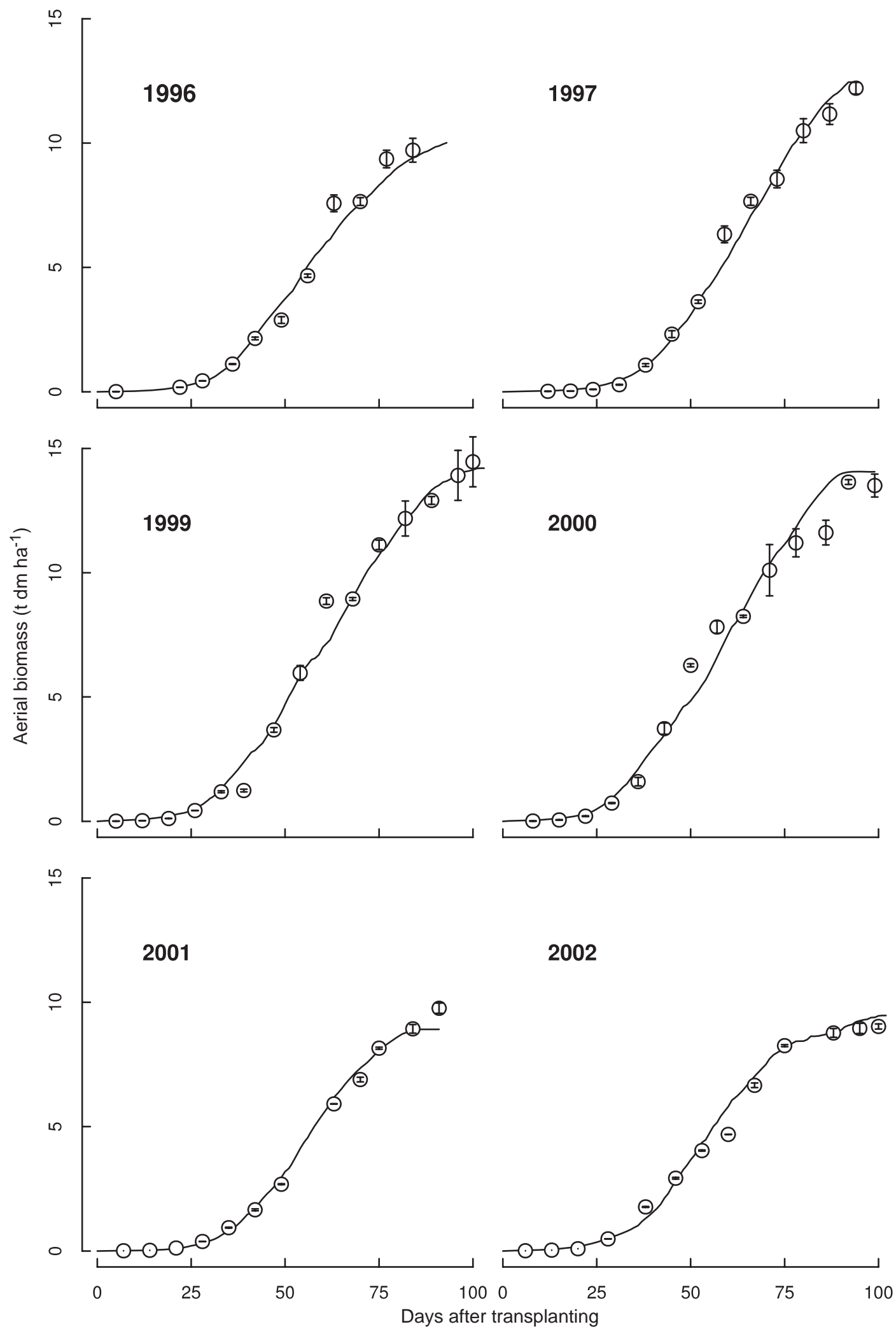

Fig. 2. Above-ground total dry biomass of processing tomato during six field experiments. Symbols show observed data, solid lines show CropSyst simulations by using the parameters reported in Table 1 . Vertical lines show standard errors.

The parameterisation of CropSyst led to a good simulation of aerial biomass (Fig. 2). As expected, the simulation is particularly good for the 1997 data, that were used for calibration (Table 2), but simulations were also good for 1996, 1999, 2000, 2001 and 2002 (Table 2).

Simulations of LAI are not as good as those for aerial biomass
(Fig. 3). The time course of LAI is always well simulated at the beginning of crop cycle, approximately until 40-50 days after transplanting, while the simulation quality decreases afterwards and, in some cases, the maximum LAI and the final decreasing trend are not fully reproduced by CropSyst. As a consequence, RRMSE and EF values are less favourable than those observed for aerial 




Fig. 3. LAI of processing tomato during six field experiments. Symbols show observed data, solid lines show CropSyst simulations by using the parameters reported in Table 1. Vertical lines show standard errors.

biomass. A similar behaviour was observed when modelling the growth of sweet pepper (Tei et al., 1996b). This confirms that the simulation of dry matter partitioning represents a crucial issue with vegetables characterised by the contemporary growth of sources and sinks (Benincasa et al., 2006). Indeed, the empirical approach used in CropSyst may be too simple with respect to the more mechanistic approaches adopted in other models (Marcelis et al., 1998; Scholberg et al., 1997; Boote and Scholberg, 2006).

However, it should be emphasized that such deviations from observed data occur during a period of time when the impact on biomass yield may not be very relevant, as it would be at the beginning of crop cycle. Furthermore, it is important to notice 
Table 1. Crop model parameters for transplanted tomato (cv. PS1296) and source of information

\begin{tabular}{|c|c|c|c|}
\hline Parameter & Ref. $^{1}$ & Value & Units \\
\hline Photosynthetic pathway & - & C3 & - \\
\hline Perennial & - & no & - \\
\hline Land use & - & row crop & - \\
\hline Aboveground biomass-transpiration coefficient (BTR) & 1997 & 10.72 & $\mathrm{~kg} \mathrm{~m}^{-3} \mathrm{kPA}$ \\
\hline Light to aboveground biomass conversion (LtBC) & 1997 & 2.38 & $\mathrm{~g} \mathrm{MJ}^{-1}$ \\
\hline Actual/potential transpiration ratio limiting leaf area growth & $\mathrm{D}$ & 0.95 & $0-1$ \\
\hline Actual to potential transpiration ratio that limits root growth & $\mathrm{D}$ & 0.50 & $0-1$ \\
\hline Optimum mean daily temperature for growth $\left(\mathrm{T}_{\mathrm{opt}}\right)$ & $\mathrm{L}$ & 20 & ${ }^{\circ} \mathrm{C}$ \\
\hline Maximum water uptake & $\mathrm{D}$ & 7 & $\mathrm{~mm} \mathrm{~d}^{-1}$ \\
\hline Leaf water potential at the onset of stomatal closure & $\mathrm{D}$ & -700 & $\mathrm{~J} \mathrm{~kg}^{-1}$ \\
\hline Wilting leaf water potential & $\mathrm{D}$ & -1200 & $\mathrm{~J} \mathrm{~kg}^{-1}$ \\
\hline Maximum rooting depth & $\mathrm{L}$ & 1 & $\mathrm{~m}$ \\
\hline Initial green LAI & 1997 & 0.010 & $m^{2} m^{-2}$ \\
\hline Maximum expected Leaf Area Index (LAI) & 1997 & 2.8 & $\mathrm{~m}^{2} \mathrm{~m}^{-2}$ \\
\hline Fraction of maximum LAI at physiological maturity & 1997 & 0.81 & $0-1$ \\
\hline Initial "LAI/DW" ratio (LAR) & 1997 & 11.516 & $\mathrm{~m}^{2} \mathrm{~kg}^{-1}$ \\
\hline Stem/leaf partition (SLP) & 1997 & 2.504 & $1-10$ \\
\hline Leaf Area Duration & 1997 & 575 & ${ }^{\circ} \mathrm{C} \mathrm{d}^{-1}$ \\
\hline Extinction coefficient for solar radiation $(\mathrm{k})$ & $\mathrm{L}$ & 0.55 & $0-1$ \\
\hline Leaf duration sensitivity to water stress & $\mathrm{D}$ & 0 & $0-3$ \\
\hline ET crop coefficient at full canopy & $\mathrm{L}$ & 1.05 & $\mathrm{~mm} \mathrm{~mm}^{-1}$ \\
\hline Degree days to overcome transplanting crisis & 1997 & 15 & ${ }^{\circ} \mathrm{C} \mathrm{d}^{-1}$ \\
\hline Degree days from emergence to flowering & 1997 & 300 & ${ }^{\circ} \mathrm{C} \mathrm{d}{ }^{-1}$ \\
\hline Degree days from emergence to maximum LAI & 1997 & 800 & ${ }^{\circ} \mathrm{C} \mathrm{d}^{-1}$ \\
\hline Degree days from emergence to begin fruit filling & 1997 & 400 & ${ }^{\circ} \mathrm{C} \mathrm{d}{ }^{-1}$ \\
\hline Degree days from emergence to maturity & 1997 & 1300 & ${ }^{\circ} \mathrm{C} \mathrm{d}{ }^{-1}$ \\
\hline Base temperature & $\mathrm{L}$ & 10 & ${ }^{\circ} \mathrm{C}$ \\
\hline Cutoff temperature & $\mathrm{L}$ & 35 & ${ }^{\circ} \mathrm{C}$ \\
\hline Phenological sensitivity to water stress & $\mathrm{D}$ & 0 & $0-3$ \\
\hline Unstressed harvest index & 1997 & 0.63 & $0-1$ \\
\hline
\end{tabular}

Table 2. Goodness of simulations expressed as Relative Root Mean Squared Error (RRMSE) and modelling efficiency (EF) for aerial biomass and LAI (Fig. 1 and Fig. 2), simulated and measured fruit yield (kg d.m. $\mathrm{ha}^{-1}$ ) of processing tomato during the six experiments. All the simulations are based on the parameterisation in Table 1

\begin{tabular}{ccccccc}
\hline Year & \multicolumn{2}{c}{ Aerial biomass } & \multicolumn{2}{c}{ LAI } & Simulated & Measured \\
& RRMSE & EF & RRMSE & EF & yield & yield \\
\hline 1996 & 13.4 & 0.976 & 17.3 & 0.92 & 6509 & 6082 \\
1997 & 8.3 & 0.991 & 13.5 & 0.97 & 7968 & 8165 \\
1999 & 9.3 & 0.998 & 14.9 & 0.95 & 9093 & 9180 \\
2000 & 12.4 & 0.976 & 17.6 & 0.94 & 8999 & 8257 \\
2001 & 12.4 & 0.976 & 15.7 & 0.96 & 5706 & 6716
\end{tabular}

that the year to year variations on LAI growth were reproduced in a satisfactory manner, which is a very interesting and promising result.

In all the cases, the simulation of final fruit yield is very good (Table 2) and differences between observed and simulated values are rather small, always below $10 \%$ apart from 2001 . This result follows the relatively constant value of the harvest index throughout years, ranging from 0.63 to 0.67 .

In conclusion, in spite of the scientific shortcuts introduced by CropSyst, it seems that, following a careful parameterisation, the practical value of this model may hold also in processing tomato, when used for management and legislative purposes. This usage is encouraged by the relatively small set of parameters required to run the simulations and by the very user-friendly interface. The set of parameters hereby reported seems to be quite robust for the environmental conditions of Central Italy and may serve as a useful starting point to run simulations in processing tomato.

\section{Acknowledgements}

The authors wish to thank Dr. Luca Bechini (University of Milano) for critically reviewing the manuscript.

\section{References}

Acock, B., D.A. Charles-Edwards, D.J. Fitter, D.W. Hand, L.J. Ludwig, J. Warren Wilson and A.C. Whiters, 1978. The contribution of leaves from different levels within a tomato crop to canopy net photosynthesis: An experimental examination of two canopy models. Journal of Experimental Botany, 29(4): 815-827.

Battilani, A. 2006. Growth indexes for fertigated processing tomato in a Mediterranean sub-humid area. Acta Horticulturae, 724: 103-110.

Benincasa, P., C. Beccafichi, M. Guiducci and F. Tei, 2006. Source-sink relationship in processing tomato as affected by fruit and nitrogen availability. Acta Horticulturae, 700: 63-66.

Boote, K.J. and J.M.S. Scholberg, 2006. Developing, parameterising and testing of dynamic crop growth models for horticultural crops. Acta Horticulturae, 718: 23-34. 
Cavero, J., R.E. Plant, G. Shennan, J.R. Williams, J.R. Kiniry and V.W. Benson, 1998. Application of EPIC model to nitrogen cycling in irrigated processing tomatoes under different management systems. Agricultural Systems, 56(4): 391-414.

Confalonieri, R. and L. Bechini, 2004. A preliminary evaluation of the simulation model CropSyst for alfalfa. European Journal of Agronomy, 21(2): 223-237.

Donatelli, M., C. Stockle, E. Ceotto and M. Rinaldi, 1997. Evaluation of CropSyst for cropping systems at two locations of northern and southern Italy. European Journal of Agronomy, 6(1-2): 35-45.

Heuvelink, E. 1996. Dry matter partitioning in tomato: Validation of a dynamic simulation model. Annals of Botany, 77(1): 71-80.

Heuvelink, E. 1999. Evaluation of a dynamic simulation model for tomato crop growth and development. Annals of Botany, 83(4): 413-422.

Jones, J.W., E. Dayan, L.H. Allen, H. Van Keulen and H. Challa, 1991. A dynamic tomato growth and yield model (TOMGRO). Transactions of the American Society of Agricultural Engineers, 34: 663-672.

Marcelis, L.F.M., E. Heuvelink and J. Goudriaan, 1998. Modelling biomass production and yield of horticultural crops: A review. Scientia Horticulturae, 74: 83-111.

Martorana, F. and G. Bellocchi, 1999. A review of methodologies to evaluate agroecosystem simulation models. Italian Journal of Agronomy, 3(1): 19-39.

Pala, M., C.O. Stockle and H.C. Harris, 1996. Simulation of Durum Wheat (Triticum turgidum ssp. durum) growth under different water and nitrogen regimes in a Mediterranean environment using CropSyst. Agricultural Systems, 51(2): 147-163.

Ramirez, A., F. Rodriguez, M. Berenguel, and E. Heuvelink, 2004. Calibration and validation of complex and simplified tomato growth models for control purposes in the Southeast of Spain. Acta Horticulturae, 654: 147-154.

Scholberg, J.M.S, K.J. Boote, J.W. Jones and B.L. McNeal, 1997. Adaptation of the CROPGRO model to simulate the growth of fieldgrown tomato. In: Systems approach for sustainable agricultural development: Application of systems approach at the field level (Kropff et al., eds.), Kluwer Academic Publishers, Doordrecht, The Netherlands, 133-151.
Scholberg, J.M.S., B.L. McNeal, J.W. Jones, K.J. Boote, C.D. Stanley and T.A. Obreza, 2000a. Growth and canopy characteristics of field grown tomato. Agronomy Journal, 92: 152-159.

Scholberg, J.M.S, B.L. McNeal, K.J. Boote, J.W. Jones, S.J. Lo Cascio and S.M. Olson, 2000b. Nitrogen stress effect on growth and nitrogen accumulation by field grown tomato. Agronomy Journal, 92: 159-167.

Stöckle, C.O., M. Donatelli and R. Nelson, 2003. CropSyst, a cropping system simulation model. European Journal of Agronomy, 18: 289-307.

Stöckle, C.O. and R. Nelson, 2003. Cropping System Simulation Model: User's Manual. Washington State University, Biological Systems Engineering Department, Washington.

Tei, F., D.P. Aikman and A. Scaife, 1996a. Growth of Lettuce, Onion and Red Beet. 2. Growth Modelling. Annals of Botany, 78(5): 645-652.

Tei, F., A. Onofri and M. Guiducci, 1996b. Simulation of sweet pepper growth based on INTERCOM: validation of the model in central Italy. In: "System analysis and simulation in Agricultural Sciences: a contribution of the RAISA Project" (Eds F. M. J. Goudriaan and H. H. van Laar), Firenze, 25-33.

Tei, F., P. Benincasa and M. Guiducci, 1999. Nitrogen fertilisation on lettuce, processing tomato and sweet pepper: yield, nitrogen uptake and the risk of nitrate leaching. Acta Horticulturae, 506: 61-67.

Tei, F., P. Benincasa and M. Guiducci, 2001. Determination of a critical nitrogen dilution curve for processing tomato. In: 2nd International Symposium on Modelling Cropping Systems, Book of proceedings (Bindi M., Donatelli M., Porter J., Van Ittersum M.K eds), Florence (Italy), 33-34.

Tei, F., P. Benincasa and M. Guiducci, 2002. Critical nitrogen concentration in processing tomato. European Journal of Agronomy, 18: 45-55.

Van Keulen, H. and E. Dayan, 1993. TOMGRO, a greenhouse tomato simulation model. Wageningen, The Netherlands: Simulation report CABO-TT No. 29, Wageningen University and Research Centre, $1-48$. 